\title{
High focal adhesion kinase expression in invasive breast carcinomas is associated with an aggressive phenotype
}

Amy L Lark ${ }^{1}$, Chad A Livasy ${ }^{1,2}$, Lynn Dressler ${ }^{2}$, Dominic T Moore ${ }^{2,3}$, Robert C Millikan²,4, Joseph Geradts ${ }^{5}$, Mary Iacocca ${ }^{6}$, David Cowan ${ }^{2}$, Debbie Little ${ }^{2}$, Rolf J Craven ${ }^{7}$ and William Cance C $^{8,9}$

${ }^{1}$ Department of Pathology, University of North Carolina at Chapel Hill, Chapel Hill, NC, USA; ${ }^{2}$ Lineberger Comprehensive Cancer Center, University of North Carolina at Chapel Hill, Chapel Hill, NC, USA; ${ }^{3}$ Department of Biostatistics, University of North Carolina at Chapel Hill, Chapel Hill, NC, USA; ${ }^{4}$ Department of Epidemiology, University of North Carolina at Chapel Hill, Chapel Hill, NC, USA; ${ }^{5}$ Department of Pathology, Roswell Park Cancer Institute, Buffalo, NY, USA; ${ }^{6}$ Christiana Care Hospital, Department of Pathology, Wilmington, DE, USA; ${ }^{7}$ Department of Molecular and Biomedical Pharmacology, University of Kentucky, Lexington, KY, USA; ${ }^{8}$ Department of Surgery, University of Florida, Gainesville, FL, USA and ${ }^{9}$ Department of Biochemistry, University of Florida, Gainesville, FL, USA

Focal adhesion kinase (FAK) is a protein tyrosine kinase expressed in invasive breast cancer that regulates antiapoptotic signaling. We have examined FAK expression by immunohistochemistry using anti-FAK 4.47 in breast tumor samples from a large population-based, case-control study of women participating in the University of North Carolina Breast Specialized Programs of Research Excellence (SPORE), Carolina Breast Cancer Study. In this population, 629 formalin-fixed, paraffin-embedded tissue sections were stained for FAK and scored as high ( $3+$ or $4+$ intensity and $\geq 90 \%$ positive cells) or otherwise. High FAK expression was associated with poor prognostic indicators including high mitotic index ( $>10$ mitoses per 10 consecutive highpower fields), nuclear grade 3, architectural grade 3, estrogen and progesterone receptor negative, and HER-2/ neu overexpressed using CB11 antibody. The association of high FAK expression with HER-2/neu overexpression lends further support that HER-2/neu and FAK collaborate to promote tumorigenesis. The presence of strong FAK expression in many high grade, estrogen- and progesterone-negative breast carcinomas indicates that FAK may be an attractive target for therapeutic intervention.

Modern Pathology (2005) 18, 1289-1294. doi:10.1038/modpathol.3800424; published online 29 April 2005

Keywords: focal adhesion kinase; breast cancer; immunohistochemistry

Tyrosine kinases, proteins that phosphorylate substrate proteins on tyrosine residues, regulate key processes in tumorigenesis, including proliferation, angiogenesis, and cellular survival. For this reason, tyrosine kinases have the potential to predict tumor progression and serve as targets for therapeutic intervention. ${ }^{1}$ While the expression patterns of tyrosine kinases such as HER-2/neu and epidermal growth factor receptor have been extensively characterized in tumors, ${ }^{2}$ the functions of other tyrosine

Correspondence: Dr W Cance, MD, Health Science Center, PO Box 100286, 1600 SW Archer Road, Gainesville, FL 32610-0286, USA. E-mail: cance@surgery.ufl.edu

Received 7 January 2005; revised and accepted 9 March 2005; published online 29 April 2005 kinases in cancer are only beginning to be understood.

Focal adhesion kinase (FAK) is a $125 \mathrm{kDa}$ protein tyrosine kinase that localizes to sites of cellular adhesion in cultured cells. FAK functions in integrin-signaling pathways, ${ }^{3-6}$ cellular motility, ${ }^{7}$ and apoptosis. ${ }^{8-10}$ The avian FAK homologue was originally identified through its association with the v-Src oncogene protein, ${ }^{11}$ suggesting a role for FAK in tumorigenesis. In our lab, human FAK was subsequently identified in high-grade sarcomas ${ }^{12}$ and breast tumors. ${ }^{13-15}$ FAK is overexpressed in a variety of human tumors in comparison with adjacent normal tissue, including breast, ${ }^{13-16}$ colon, ${ }^{13,14,17,18}$ thyroid, ${ }^{19}$ ovarian, ${ }^{20}$ cervix, ${ }^{16}$ head and neck, ${ }^{21}$ and esophagus. ${ }^{22}$ 
Early work suggested that FAK might function in the later stages of tumor progression, such as invasion and metastasis, promoting adhesion in invading cells. However, FAK expression is detected in early stage tumors, such as ductal carcinoma in situ ${ }^{15}$ suggesting that FAK might have functions in cancer progression that precede invasion and metastasis. Work from this lab and others has demonstrated that FAK regulates antiapoptotic survival signaling, even in cells maintained in the absence of adhesion. ${ }^{23,24}$ This suggests that FAK could function in the earlier stages of tumor progression as a regulator of survival, suppressing apoptotic responses associated with uncontrolled proliferation and signaling.

In the present study, we have analyzed the expression of FAK in a large population-based study of breast tumor samples. Although we had previously shown FAK overexpression in breast tumors ${ }^{13-15}$ the previous studies lacked sufficient numbers of patient samples to derive relationships between FAK expression and other important clinical markers.

\section{Materials and methods}

\section{Study Population}

The Carolina Breast Cancer Study is a populationbased, case-control study whose study participants included women 20-74 years of age from 24 contiguous counties of central and eastern North Carolina. ${ }^{25,26}$ Using the North Carolina Central Cancer Registry, 1153 women with a first diagnosis of invasive breast cancer between 1993 and 1996 were identified. ${ }^{27}$ African-American and women under the age of 50 years were over-sampled using randomized recruitment. Informed consent was obtained and 861 invasive breast cancer cases were eligible for participation in Phase 1 of Carolina Breast Cancer Study, overall response rate $=75 \%$. Medical records or direct histopathological review of tumor tissue provided clinical data and information about tumor characteristics. The University of North Carolina School of Medicine Institutional Review Board approved all aspects of this research.

\section{Tissue Specimens}

Formalin-fixed, paraffin-embedded tumor blocks were obtained from participating hospitals' pathology departments and tumors were sectioned by the Specialized Programs of Research Excellence (SPORE) Immunohistochemistry Core facility as described previously. ${ }^{28}$ All sections were stored at $4^{\circ} \mathrm{C}$. Of the 861 formalin-fixed, paraffin embedded specimens received for the Carolina Breast Cancer Study, 629 were available and contained sufficient invasive cancer for FAK immunohistochemistry.

\section{Immunohistochemistry}

FAK immunohistochemistry was performed using the monoclonal antibody 4.47 (1:250; Upstate Biotechnology, Lake Placid, NY, USA) to the amino-terminal region of FAK. ${ }^{14}$ This region of FAK is preferred as an antigenic target since antiFAK antibodies directed at the carboxy terminus of the FAK molecule do not distinguish between FAK and FAK-related nonkinase (FRNK) proteins. ${ }^{14}$ The 4.47 antibody has been previously characterized and recognizes FAK in formalin-fixed, paraffinembedded breast tumor sections, with minimal crossreactivity. ${ }^{14}$

FAK immunohistochemical analyses were performed as described previously. ${ }^{18}$ Briefly, slides were incubated overnight with anti-FAK 4.47 monoclonal antibody (1:250; Upstate Biotechnology) after heat-induced epitope recovery and blocking with normal horse serum (Vectastatin Elite Kit; Vector Laboratories, Burlingame, CA, USA). The DAKO Autostainer (DAKO Corporation) was utilized for application and incubation of the biotinylated horse antimouse IgG (Vectastain Elite Kit, Vector Laboratories), avidin-biotin complex (Vectastain Elite Kit, Vector Laboratories), and slate gray chromagen (Vector Laboratories).

HER-2/neu immunohistochemistry had been previously performed in the SPORE Immunohistochemistry laboratory using clone CB11 (1:100; BioGenex, San Ramon, CA, USA). ${ }^{29}$ These assays were scored previously (LG and MI) and results maintained in the SPORE Immunohistochemistry database. Immunohistochemistry was performed using an avidin-biotin immunoperoxidase system with $3^{\prime}, 3^{\prime}$ diaminobinzidine as chromagen. Briefly, slides were incubated overnight with clone CB11 after quenching endogenous peroxidase using a methanol-peroxide bath and blocking with normal horse serum (Vectastain Elite Kit, Vector Laboratories). During day 2, slides were incubated with biotinylated secondary antibody (Vectastain Elite Kit, Vector Laboratories), avidin-biotin complex (Vectastain Elite Kit, Vector Laboratories), and $3^{\prime}, 3^{\prime}$ diaminobinzidine (Sigma, St Louis, MO, USA). Cases were considered positive for HER-2/neu if there was unambiguous membrane staining of a weak, moderate, or strong intensity in at least $10 \%$ of the invasive cancer cells.

\section{Immunohistochemistry Scoring for FAK}

A single board-certified pathologist (CAL) scored each tissue section for FAK expression based on a scoring system that measured intensity ( 0 , none; 1 , borderline; 2 , weak; 3 , moderate; 4 , strong), percentage positive cells (0-100), and cellular localization (nucleus, cytoplasm, membrane, or combination). In order to better define FAK expression in a large study population, we dichotomized FAK expression as high $(3+$ or $4+$ intensity and $\geq 90 \%$ positive 
cells) and not high (0, 1 , or 2 intensity and/or $<90 \%$ positive cells) (Figure 1).

\section{Statistical Methods}

Fisher's exact test was used for data categorized into two by two contingency tables. For the larger
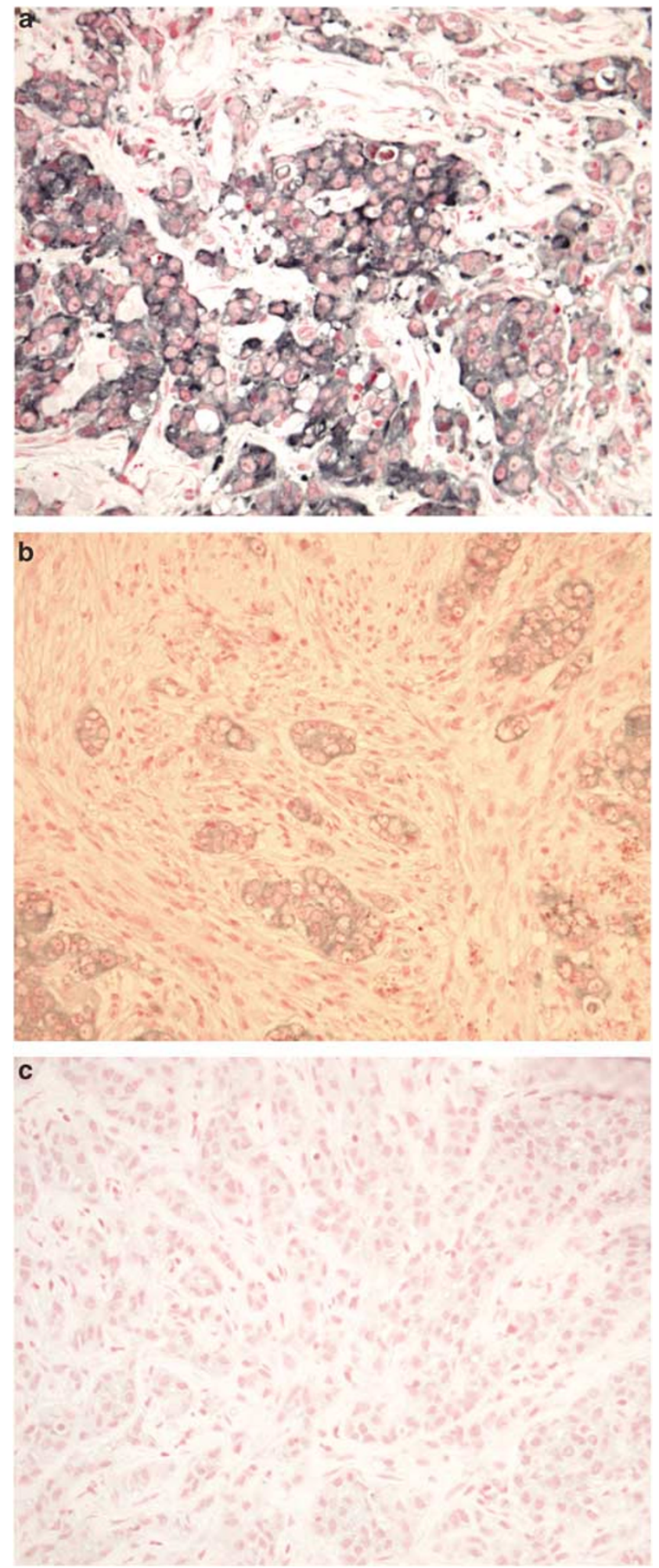

contingency tables (ie the two by three and two by four tables of mitotic index, nuclear grade, histological grade, and stage at diagnosis by dichotomized FAK expression), we used the nonparametric Jonckheere-Terpstra method to test for ordered differences. With this test, the null hypothesis is that the distribution of the response does not differ across ordered categories. Statistical analyses were performed with SAS statistical software, Version 8.2, SAS Institute Inc., Cary, NC, USA. Logistic regression was implemented using SAS version 6.11 (SAS Institute Inc.) to estimate odds ratios for the association of high FAK expression with the following potential predictive variables: race, menopausal status, stage at diagnosis, lymph node status, nuclear grade, histologic grade, mitotic index, HER2/neu expression, and estrogen receptor (ER) status. Models were adjusted for age.

\section{Results}

Formalin-fixed, paraffin-embedded tumor blocks were obtained for 629 (73\%) of 861 tumors of breast cancer patients who consented to participate in Phase 1 of Carolina Breast Cancer Study. Among the 629 Carolina Breast Cancer Study breast cancer patients, $41 \%$ were African-American and 52\% were premenopausal ${ }^{30}$ (Table 1). The mean age was 48 years (minimum age 23 years, maximum age 74 years; Table 1). The majority of these women presented with stage 1 or 2 disease $(89 \%)^{31}$ and negative lymph nodes $(60 \%$, Table 1$)$. The majority of the breast cancers were poorly differentiated $(65 \%)$ with moderate to marked nuclear pleomorphism $(88 \%$, Table 1), ER (59\%) and progesterone receptor (PR; 57\%) positive, and negative for HER-2/ neu overexpression $77 \%$ (Table 2 ). In all, $25 \%$ of the breast tumors demonstrated high FAK expression (Table 2). In this study population, recurrence and survival data have not been compiled to date.

Tumors that expressed high levels of FAK (Table 3) were compared with other clinicopathological features. High FAK expression was highly associated with a mitotic index of $>10$ mitoses per 10 consecutive high-power fields $(P<0.0001)$ and nuclear grade 3 breast tumors $(P<0.0001)$. Breast tumors with high FAK expression were also more

\footnotetext{
Figure 1 Immunohistochemical analysis of FAK expression in invasive breast cancer. Anti-FAK 4.47 monoclonal antibody (1:250) was used to detect FAK expression with slate gray chromagen. Tissue sections for FAK expression is based on a scoring system that measured intensity ( 0 , none; 1 , borderline; 2 , weak; 3, moderate; 4, strong), percentage positive cells (0-100), and cellular localization (nucleus, cytoplasm, membrane, or combination). FAK expression was dichotomized as high ( $3+$ or 4 + intensity and $\geqslant 90 \%$ positive cells) or not high. (a) FAK expression in invasive breast cancer demonstrating strong cytoplasmic expression ( $\times 400$ magnification). (b) Weak FAK expression demonstrated by faint cytoplasmic staining within invasive breast cancer cells ( $\times 400$ magnification). (c) No FAK expression demonstrated in breast cancer cells ( $\times 400$ magnification).
} 
Table 1 Characteristics of breast cancer patients in the CBCS with FAK data

\begin{tabular}{|c|c|}
\hline Characteristic & Number (\%) \\
\hline Number of cases & 629 \\
\hline Age (mean) & 48 \\
\hline Minimum & 23 \\
\hline Maximum & 74 \\
\hline \multicolumn{2}{|l|}{ Race } \\
\hline African-American & $261(41 \%)$ \\
\hline Non African-American & $368(59 \%)$ \\
\hline \multicolumn{2}{|l|}{ Menopausal status } \\
\hline Premenopausal & $328(52 \%)$ \\
\hline Postmenopausal & $301(48 \%)$ \\
\hline \multicolumn{2}{|l|}{ Stage at diagnosis ${ }^{\mathrm{a}}$} \\
\hline 1. Stage I & 227 (39\%) \\
\hline 2. Stage IIA, IIB & $292(50 \%)$ \\
\hline 3. Stage IIIA, IIIB & $50(8 \%)$ \\
\hline 4. Stage IV & $15(3 \%)$ \\
\hline \multicolumn{2}{|l|}{ Mitotic index } \\
\hline 1. $\leq 5$ mitoses & $264(42 \%)$ \\
\hline 2. $6-10$ mitoses & $85(14 \%)$ \\
\hline 3. $>10$ mitoses & $273(44 \%)$ \\
\hline \multicolumn{2}{|l|}{ Nuclear grade } \\
\hline 1. Slight pleomorphism & $76(12 \%)$ \\
\hline 2. Moderate pleomorphism & $289(46 \%)$ \\
\hline 3. Marked pleomorphism & $261(42 \%)$ \\
\hline \multicolumn{2}{|l|}{ Histological grade } \\
\hline 1. (Well differentiated) & $37(6 \%)$ \\
\hline 2. (Moderately differentiated) & $180(29 \%)$ \\
\hline 3. (Poorly differentiated) & $408(65 \%)$ \\
\hline \multicolumn{2}{|l|}{ Lymph node status } \\
\hline Positive & $239(40 \%)$ \\
\hline Negative & $360(60 \%)$ \\
\hline
\end{tabular}

${ }^{a}$ AJCC Cancer Staging Handbook, 5th Edition.

Table 2 Tumor marker expression in CBCS breast cancer patients

\begin{tabular}{ll}
\hline Marker & Number (\%) \\
\hline FAK & \\
$\quad$ High $^{\mathrm{a}}$ & $154(25 \%)$ \\
Not High $^{\mathrm{b}}$ & $475(76 \%)$ \\
& \\
Estrogen receptor & $355(59 \%)$ \\
$\quad$ Positive & $251(41 \%)$ \\
$\quad$ Negative & \\
Progesterone receptor & $340(57 \%)$ \\
$\quad$ Positive & $261(43 \%)$ \\
$\quad$ Negative & \\
HER-2/neu & $145(23 \%)$ \\
$\quad$ Positive & $481(77 \%)$ \\
Negative & \\
\hline
\end{tabular}

${ }^{\mathrm{a}}$ FAK high $=3+$ or $4+$ intensity and $\geq 90 \%$ positive cells.

${ }^{\mathrm{b}}$ FAK not high $=0,1,2$ intensity and/or $<90 \%$ positive cells.
Table 3 Correlation between FAK immunohistochemical expression and clinicopathological features

\begin{tabular}{|c|c|c|c|c|}
\hline $\begin{array}{l}\text { Clinicopathological } \\
\text { feature }\end{array}$ & Total & $F A K h_{i g h}{ }^{\mathrm{a}}$ & $\begin{array}{c}\text { FAK not } \\
\text { high }^{\mathrm{b}}\end{array}$ & $\mathrm{P}$-value \\
\hline \multicolumn{5}{|l|}{ Mitotic index } \\
\hline 1. $\leq 5$ mitoses & 264 & $34(13 \%)$ & $230(87 \%)$ & \\
\hline 2. $6-10$ mitoses & 85 & $25(29 \%)$ & $60(71 \%)$ & \\
\hline 3. $>10$ mitoses & 273 & $93(34 \%)$ & $180(66 \%)$ & $<0.0001$ \\
\hline \multicolumn{5}{|l|}{ Nuclear grade } \\
\hline $\begin{array}{l}\text { 1. Slight } \\
\text { pleomorphism }\end{array}$ & 76 & $6(0.08 \%)$ & $70(92 \%)$ & \\
\hline $\begin{array}{l}\text { 2. Moderate } \\
\text { pleomorphism }\end{array}$ & 289 & $51(18 \%)$ & $238(82 \%)$ & \\
\hline $\begin{array}{l}\text { 3. Marked } \\
\text { pleomorphism }\end{array}$ & 261 & $96(37 \%)$ & $165(63 \%)$ & $<0.0001$ \\
\hline \multicolumn{5}{|l|}{ Histological grade } \\
\hline $\begin{array}{l}\text { 1. Well } \\
\text { differentiated }\end{array}$ & 37 & $3(0.08 \%)$ & $34(92 \%)$ & \\
\hline $\begin{array}{l}\text { 2. Moderately } \\
\text { differentiated }\end{array}$ & 180 & $41(23 \%)$ & $139(77 \%)$ & \\
\hline $\begin{array}{l}\text { 3. Poorly } \\
\text { differentiated }\end{array}$ & 408 & $109(27 \%)$ & $299(73 \%)$ & 0.038 \\
\hline \multicolumn{5}{|l|}{ Stage at diagnosis ${ }^{c}$} \\
\hline 1. Stage I & 227 & $45(20 \%)$ & $182(80 \%)$ & \\
\hline 2. Stage IIA, IIB & 292 & $75(26 \%)$ & $217(74 \%)$ & \\
\hline 3. Stage IIIA, IIIB & 50 & $15(30 \%)$ & $35(70 \%)$ & \\
\hline 4. Stage IV & 15 & $3(20 \%)$ & $12(80 \%)$ & 0.08 \\
\hline \multicolumn{5}{|l|}{ Lymph node status } \\
\hline Positive & 239 & $69(29 \%)$ & $170(71 \%)$ & \\
\hline Negative & 360 & $79(22 \%)$ & $281(78 \%)$ & 0.066 \\
\hline \multicolumn{5}{|l|}{ Estrogen receptor } \\
\hline Positive & 355 & $71(20 \%)$ & $284(80 \%)$ & \\
\hline Negative & 251 & $78(31 \%)$ & $173(69 \%)$ & 0.002 \\
\hline \multicolumn{5}{|l|}{ Progesterone receptor } \\
\hline Positive & 340 & $65(19 \%)$ & $275(81 \%)$ & \\
\hline Negative & 261 & $83(32 \%)$ & $178(68 \%)$ & 0.0004 \\
\hline \multicolumn{5}{|l|}{ HER-2/neu } \\
\hline Positive & 145 & $49(34 \%)$ & $96(66 \%)$ & \\
\hline Negative & 481 & $105(22 \%)$ & $376(78 \%)$ & 0.004 \\
\hline
\end{tabular}

${ }^{\mathrm{a}}$ FAK high $=3+$ or $4+$ intensity and $\geq 90 \%$ positive cells.

${ }^{\mathrm{b}} \mathrm{FAK}$ not high $=0,1,2$ intensity and/or $<90 \%$ positive cells.

${ }^{\mathrm{c}}$ AJCC Cancer Staging Handbook, 5th Edition.

likely to be architectural grade 3 tumors $(P=0.038$, Table 3).

FAK expression was also associated with several markers of poor prognosis. Breast tumors expressing high levels of FAK were associated with ER negative $(P=0.002)$ and $P R$ negative $(P=0.0004$, Table 3$)$ phenotype. In addition, high FAK expression was associated with overexpression of the tyrosine kinase receptor HER-2/neu $(P=0.004$, Table 3). After multivariable adjustment, the only significant predictors of breast tumors with high FAK expression were HER-2/neu positivity (2.2 (1.4-3.4), $P=0.001)$ and nuclear grade 3 tumors (2.3 (1.44.0), $P=0.002$ ). 
In the Carolina Breast Cancer Study population, patients presenting at diagnosis with stage 3 or 4 breast cancers (65/584) (American Joint Committee on Cancer, 5th Edition, Cancer Staging Classification for Breast Cancer Stages IIIA, IIIB, or IV) were more likely to have tumors with high FAK expression $(P=0.08)$. Patients presenting with positive lymph nodes were also more likely to have breast tumors with high FAK expression $(P=0.066)$. Although not statistically significant, high FAK expression is common in advanced stage.

\section{Discussion}

We have examined the characteristics of a population-based, case-control study of breast cancer. High FAK expression in the Carolina Breast Cancer Study breast tumors is associated with a poor prognostic phenotype. Histologically, these tumors have a high mitotic index $(<10$ mitoses per high power field), grade 3 nuclear and architectural features, lack ER and PR, and overexpress HER-2/neu. To date, recurrence and survival data for this Carolina Breast Cancer Study population is not available in order to evaluate FAK as a prognostic marker.

Overexpression of HER-2/neu is usually associated with a worse prognosis in primary breast cancer and is observed in 15-30\% of breast cancers. ${ }^{32-34}$ In the current study of Carolina Breast Cancer Study patients, $23 \%$ of breast cancers overexpressed HER-2/neu. The association of high FAK expression with HER-2/neu overexpression suggests that high FAK expression may also be a poor prognostic marker. Even though the molecular interactions between FAK and HER-2/neu signaling are just beginning to be understood, work by Vadlamudi et $a l^{35}$ suggest that HER-2/neu and heregulin are involved in FAK signaling and selectively upregulate FAK tyrosine phosphorylation.

Work from this lab and others has indicated a role for FAK in survival signaling, which is the propagation of signals that are required to maintain viability and suppress apoptosis. Attenuation of FAK expression with antisense oligonucleotides leads to apoptosis in tumor cells but not in nontransformed cell lines. ${ }^{8}$ Subsequent work has utilized overexpression of a fragment of the FAK carboxy-terminal domain (FRNK or FAK-CD for FAK-carboxy-terminal domain) that acts as a dominant-negative protein. FRNK/FAK-CD leads to the inhibition of endogenous FAK phosphorylation ${ }^{36}$ and the degradation of FAK in tumor cells. ${ }^{23,37}$ As a result, FRNK/FAK-CD leads to apoptotic cell death in colon ${ }^{37}$ and breast cancer cells, ${ }^{23}$ but not in normal nontumor cells. ${ }^{23,37}$ Furthermore, FRNK/FAK-CD inhibits apoptosis even in cells maintained in suspension, indicating a role for FAK in suppression of apoptosis even in the absence of adhesive signaling. Expression of the $\mathrm{N}$-terminus of FAK in breast carcinoma cell lines resulted in rounding, detachment and apoptosis. ${ }^{38}$ Recent work has shown FAK association with receptor-interacting protein, a serine/threonine kinase that contains a death domain. ${ }^{39}$ When FAK binds to receptor-interacting protein, the proapoptotic signals supplied by receptor-interacting protein are suppressed. This further supports the role of FAK as a survival signal. ${ }^{39}$

In this study, high FAK expression had a borderline association with positive lymph node status and stage at diagnosis. Owing to the low number of patients presenting with stage III and IV disease we cannot confirm this association in this study. However, since high FAK was associated with other poor prognostic indicators, examining a population with higher numbers of stage III and IV disease would be worthwhile. Miyazaki et $a l^{22}$ reported an association between FAK overexpression (intense staining of $>40 \%$ of carcinoma cells) and lymph node metastasis in esophageal squamous cell carcinoma. Indeed, the mechanistic framework of FAK as a survival signal would suggest a role for FAK in metastatic spread to lymph nodes and such a role has been observed in esophageal carcinoma. ${ }^{22}$

These results also emphasize the potential of FAK as a molecular target for cancer therapeutics. Although we dichotomized FAK expression as high or not high, our cutoff for high FAK was expression in at least $90 \%$ of cells, with an intensity of $3+$ or $4+$. Moreover, normal breast cells express negligible levels of FAK, demonstrating a 'therapeutic window' between normal and tumor cells. Taken together, our results demonstrate the aggressive phenotype of high FAK expression and offer the potential for therapeutics designed to abrogate its function.

\section{Acknowledgements}

Research supported by NIH Grant RO1 65910 and Specialized Program of Research Excellence (SPORE) in Breast Cancer, NIH/NCI P50-CA 58223. We thank the UNC SPORE Tissue Procurement and Analysis Core Facility of the University of North Carolina Lineberger Comprehensive Cancer Center for training, technical support, and use of laboratory equipment. We also thank Jessica Tse for statistical assistance.

\section{References}

1 Garcia-Echeverria C, Fabbro D. Therapeutically targeted anticancer agents: inhibitors of receptor tyrosine kinases. Mini Rev Med Chem 2004;4:273-283.

2 Mass RD. The HER receptor family: a rich target for therapeutic development. Int J Radiat Oncol Biol Phys 2004;58:932-940.

3 Kornberg L, Earp HS, Parsons JT, et al. Cell adhesion or integrin clustering increases phosphorylation of a focal adhesion-associated tyrosine kinase. J Biol Chem 1992; 267:23439-23442. 
4 Lipfert L, Haimovich B, Schaller MD, et al. Integrindependent phosphorylation and activation of the protein tyrosine kinase pp125FAK in platelets. J Cell Biol 1992;119:905-912.

5 Schlaepfer DD, Hanks SK, Hunter T, et al. Integrinmediated signal transduction linked to Ras pathway by GRB2 binding to focal adhesion kinase. Nature 1994; 372:786-791.

6 Guan JL. Role of focal adhesion kinase in integrin signaling. Int J Biochem Cell Biol 1997;29:1085-1096.

7 Cary LA, Chang JF, Guan JL. Stimulation of cell migration by overexpression of focal adhesion kinase and its association with Src and Fyn. J Cell Sci 1996; 109:1787-1794.

$8 \mathrm{Xu} \mathrm{LH}$, Owens LV, Sturge GC, et al. Attenuation of the expression of the focal adhesion kinase induces apoptosis in tumor cells. Cell Growth Differ 1996;7:413-418.

9 Firsch SM, Vuori K, Ruoslahti E, et al. Control of adhesion-dependent cell survival by focal adhesion kinase. J Cell Biol 1996;134:793-799.

10 Hungerford JE, Compton MT, Matter ML, et al. Inhibition of pp125FAK in cultures fibroblasts results in apoptosis. J Cell Biol 1996;135:1383-1390.

11 Schaller MD, Borgman CA, Cobb BS, et al. pp125fak a structurally distinctive protein-tyrosine kinase associated with focal adhesions. Proc Natl Acad Sci USA 1992;89:5192-5196.

12 Weiner TM, Liu ET, Craven RJ, et al. Expression of growth factor receptors, the focal adhesion kinase, and other tyrosine kinases in human soft tissue tumors. Ann Surg Oncol 1994;1:18-27.

13 Owens LV, Xu L, Craven RJ, et al. Overexpression of the focal adhesion kinase (p125FAK) in invasive human tumors. Cancer Res 1995;55:2752-2755.

14 Cance WG, Harris JE, Iacocca MV, et al. Immunohistochemical analyses of focal adhesion kinase expression in benign and malignant human breast and colon tissues: correlation with preinvasive and invasive phenotypes. Clin Cancer Res 2000;6:2417-2423.

15 Lightfoot Jr M, Lark A, Livasy CA, et al. Upregulation of focal adhesion kinase (FAK) expression in ductal carcinoma in situ (DCIS) is an early event in breast tumorigenesis. Breast Cancer Res Treat 2004;88:109-116.

16 Oktay MH, Oktay K, Hamele-Bena D, et al. Focal adhesion kinase as a marker of malignant phenotype in breast and cervical carcinomas. Hum Pathol 2003;34: 240-245.

17 Han NM, Fleming RY, Curley SA, et al. Overexpression of focal adhesion kinase (p125FAK) in human colorectal carcinoma liver metastases: independence from c-src or c-yes activation. Ann Surg Oncol 1997;4:264-268.

18 Lark AL, Livasy CA, Calvo B, et al. Overexpression of focal adhesion kinase in primary colorectal carcinomas and colorectal liver metastases. Clin Cancer Res 2003; 9:215-222.

19 Owens LV, Xu L, Dent GA, et al. The focal adhesion kinase as a marker of invasive potential in differentiated human thyroid cancer. Ann Surg Oncol 1996;3: 100-105.

20 Judson PL, He X, Cance WG, et al. Overexpression of focal adhesion kinase, a protein tyrosine kinase, in ovarian carcinoma. Cancer 1999;86:1551-1556.

21 Kornberg LJ. Focal adhesion kinase and its potential involvement in tumor invasion and metastasis. Head Neck 1998;20:745-752.
22 Miyazaki T, Kato H, Nakajima $M$, et al. FAK overexpression in correlated with tumour invasiveness and lymph node metastasis in oesophageal squamous cell carcinoma. Br J Cancer 2003;89:140-145.

$23 \mathrm{Xu} \mathrm{LH}$, Yang X, Bradham CA, et al. The focal adhesion kinase suppresses transformation-associated, anchorage-independent apoptosis in human breast cancer cells. J Biol Chem 2000;275:30597-30604.

24 Ilic D, Almeida EAC, Schlaepfer DD, et al. Extracellular matrix survival signals transduced by focal adhesion kinase suppress p53-mediated apoptosis. J Cell Biol 1998;143:547-560.

25 Conway K, Edmiston SN, Cui L, et al. evalence and spectrum of p53 mutations associated with smoking in breast cancer. Cancer Res 2002;62:1987-1995.

26 Millikan R, Eaton A, Worley K, et al. HER2 codon 655 polymorphism and risk of breast cancer in African Americans and whites. Breast Cancer Res Treat 2003; 79:355-364.

27 Furberg H, Millikan R, Dressler L, et al. Tumor characteristics in African American and white women. Breast Cancer Res Treat 2001;68:33-43.

28 Dressler LG, Geradts J, Burroughs M, et al. Policy guidelines for the utilization of formalin-fixed, paraffin-embedded tissue sections: the UNC SPORE experience. Breast Cancer Res Treat 1999;58:31-39.

29 Muss HB, Thor AD, Berry DA. c-erbB-2 expression and response to adjuvant therapy in women with nodepositive early breast cancer. N Engl J Med 1994;330: 1260-1266.

30 Millikan R, Pittman G, Newman B. Cigarette smoking, $N$-acteyltransferases 1 and 2, and breast cancer risk. Cancer Epidemiol Biomarkers Prev 1998;7: 371-378.

31 Fleming I, Cooper J, Henson D. AJCC Cancer Staging Handbook, 5th edn. Lippincott-Raven: New York, 1998.

32 King CR, Kraus MH, Aaronson SA. Amplification of a novel v-erbB-related gene in a human mammary carcinoma. Science 1985;229:974.

33 Slamon DJ, Clark GM, Wong SJ, et al. Human breast cancer: correlation of relapse and survival with amplification of the HER-2/neu oncogene. Science 1987;235:177-182.

34 Slamon DJ, Godolphin W, Jones LA. Studies of the HER-2/neu protooncogene in human breast and ovarian cancer. Science 1989;244:707-712.

35 Vadlamudi RK, Sahin AA, Adam L, et al. Heregulin and HER2 signaling selectively activates C-Src phosphorylation at tyrosine 215. FEBS Lett 2003;543: 76-80.

36 Richardson A, Parson TA. A mechanism for regulation of the adhesion-associated protein tyrosine kinase pp125FAK. Nature 1996;380:538-540.

37 Golubovskaya VM, Gross S, Kaur AS, et al. Simultaneous inhibition of focal adhesion kinase and SRC enhances detachment and apoptosis in colon cancer cell lines. Mol Cancer Res 2003;10:755-764.

38 Beviglia L, Golubovskaya V, Xu L, et al. Focal adhesion kinase $N$-terminus in breast carcinoma cells induces rounding, detachment and apoptosis. Biochem J 2003; 373:201-210.

39 Kurenova E, Xu LH, Yang X, et al. Focal adhesion kinase suppresses apoptosis by binding to the death domain of receptor-interacting protein. Mol Cell Biol 2004;24:4361-4371. 